\title{
The Social as Human: on the Question of Negative Metaphysics of the Social
}

\author{
Natalia Tereshchenko \\ Kazan Federal University \\ Kazan, Russia \\ E-mail: tereshenko_tata@mail.ru
}

\author{
Tatiana Shatunova \\ Kazan Federal University \\ Kazan, Russia \\ E-mail: shatunovat@mail.ru
}

\begin{abstract}
The social-philosophic research heuristic potential of the Social Phenomenon is shown in the article. The analysis prospects in the context of negativity metaphysics are disclosed. The authors show possible options of human meanings of the Social in the conditions of its crisis by means of aestheticization of social life forms of the modern person.
\end{abstract}

Keywords - the Social; metaphysics of negativity; practical metaphysics; the Aesthetic; aestheticization of social life

\section{INTRODUCTION}

Since the 70s-80s of the last century the "Social" concept has been in the focus of research of almost entire social philosophy as its special and main subject ${ }^{1}$. This formulation of the question about the subject of its analysis distinguishes nonclassical social philosophy from classic one whose proclaimed subject is society. V.A. Konev wrote that it is incorrect to define society as an object of social philosophy because philosophy that self-determines through the phenomenon of society is partially unfaithful to itself as it ceases to seek the general, the totality as being, and refers only to a specifically allocated part of the totality. Responding to this request, nonclassical social philosophy has made the Social its main subject as a way of human being-in-the world [2. 14].

The space grasped by the "Social" concept comprises not only relations between social groups, interrelations of the subjects of history; not only the so-called social sphere. The concept of the Social is also not limited to designation of the whole world of the social in its institutional form as the aggregate of social institutions that have emerged in capitalist society under the sign of "the birth of the social" [see: 3]. Today we appeal to the Social as a "relation to the social relation" [4. p.167-208]. This approach to the Social is a display of an increasing role of the subjective factor in contemporary social development in the situation when the subjective factor itself becomes an objective necessity of the development. The subjective factor represents a measure of subjective participation of man in the objective course of things: the degree of his participatory consciousness and participatory action. The personal forms of social relations (when the Social is perceived as the most important, as a

${ }^{1}$ P.K.Grechko took a direct participation in formation of the new tradition [see: 1]. space of personal responsibility of man for an action and thought) are formed in this action.

\section{CRISIS OF THE MODERN SOCIAL}

In the Modern age man not only creates his Social by himself but also knows it as the product of his own creative mind, he realizes that with the help of reason as an artificially created instrument he forms a twofold artificial formation - society. The paradox is that this construction is carried out in the form of civilization - a system of social institutions functioning as an aggregate entity or system of elements aimed at man's mastering of the objective development of social relations. Here we note a transfer of an imperative subject-object relation to the sphere of the Social. The transfer makes it possible to understand why the Social was perceived traditionally as anti-human, as an impediment to the development of man's personality, as an imperative structure dominating over it, at the limit - as an extreme form of this domination. The matter is that the transfer is far from being just a theoretical move. The extreme form of this domination is alienated, transformed forms of social reality created by man but phantasmatically directed against him. It is a foggy and illusory realm of the 'irony of history' law.

Perhaps, antisociality or a-sociality of some directions of nonclassical philosophy is directed against the tinge of domination, which, by the way, was expressed in an intention of the "ontological turn" in which the laws of being were viewed as unrelated to institutionally, civilizationally treated sociality. Perhaps, this vision was one of the reasons for criticizing the subject's metaphysics. However, the development of this logic (certainly "including": some other reasons) resulted in the situation where peculiar continuation of the ontological turn in the beginning of the XXI century led to attempts to expand the concept of the Social, to blur the boundaries of this concept by extending it to all kinds of relations. For example, B. Latour extends the concept of the Social to include "humans and nonhumans" [5. P. 23]. Thus, modern philosophy and social theory as well want to combine two opposing ideas: to expand the Social beyond the social world and to destroy it through reduction of qualitative differences in the modes of being. In any case, love, death, all human absolutes are understood as having no relation to sociality. 
In reality, we prevalently suffer from lack of sociality, from its shortage rather than from sociality of the Social. The everyday forms of such a shortage are underdevelopment or inavalability of institutional structures including imperative ones that carry out quite specific social functions. The extreme, finite form of such a shortage is the situation when society betrays a man leaving him to the mercy of fate. In this context Erich Soloviev's writings about the lost generation are based on the analysis of books by E. Hemingway. And later the fate of the lost generation was shared by Afghan, Chechen militants, Vietnamese veterans in the USA, and other combatants.

The actual living community as a form of sociality is also in crisis, it also does not work. Thus, for example, Fordism, which is understood not only as a system of lifelong coexistence of an employer and an employee within the framework of a single enterprise with constant retraining of personnel, but also expansively as a form of collective, clearly regulated action, is over. All forms of collective work today are perceived as a game at best, and are treated negatively at worst.

"The era of the individual" (A. Renaut) has come, and forms of compatibility of any kind do not work. In this sense, postmodern philosophy is right when insists that it is impossible to base the future on the past and only on the past. As for the institutional forms, they are already the past, though, of course, it is adaptable in the present not only because of inertia and possession of imperative mechanisms, but also due to the objective necessity of these forms.

The limiting form of absence (lack) of the social is the absence of forms of community and sociality adequate to the nature/structure and features of modern man. If we understand the Social as "relation to the social relation", the lack of sociality is blocking of relations of involvement, fragmentation which does not allow to realize the relation, since to know is not enough, it is still necessary to realize the known.

The absence of an adequate form of sociality can also be presented as a shortage of the aesthetic element of social processes. Rejection of this form inevitably affects the content because the social as an artificial entity always represents the ability of being-with-others (Heidegger) to some extent. The classical era of sociality development is the XVIII century, the era of the Enlightenment and, according to Foucault, the era of the power of supervision is characterized by the fact that art is often thought of as a mimetic phenomenon, and it is not accidental: society itself is mimetically-reflective and "transparent" at this time. The Institute of Education, school reproduce the features of monastic and military life at the same time; the army trains in military science, and this is a school of military service; monasteries are involved in teaching as school is; the hospital resembles barracks in their organizational structure. In order to obey the power of vision (supervision) society must be apt for viewing: the structures should be similar (homogeneous), in a way they should reproduce each other and somehow reflect each other, imitate each other, and, therefore, be related mimetically. Thus, mimesis being a principle of art is simultaneously a principle of organization and functioning of society, and "the mimetic nature of art" in fact turns out to be a historical form of art typical precisely for the Modern Age ${ }^{2}$.

\section{SOCIAL AS METAPHYSICAL}

So, the first historical form of the developed New European sociality is formed according to the mimetic principle of interrelations of similar macrostructures. The aesthetic principle as a living form is transposed into the space of the Social.

Today, the Social of the Modern Age is questioned due to the crisis of institutions in conditions of mass society. In social theory this fact is represented in well-known ideas of the impossibility of society [6] and the end of the Social [7]. Baudrillard writes about the death of the Social under the influence of the all-consuming mass. However, we can say that the death of the Social is not absolute, and the idea itself is more likely an expression of crisis of the social form in its institutional manifestation [see: 4. P.202-203]. The social institutions, of course, have not disappeared, but they have ceased to reproduce their human, metaphysical purpose. The ideas produced by the very existence of some social institutions are also beginning to corrode. So, for example, the idea of patriotism is being devalued, and it is expressed in absolutization of the phrase "patriotism is the last resort of a scoundrel" which has become popular in the rhetoric of our domestic opposition. These words were uttered by Dr. Samuel Johnson in 1775 in a very specific situation when any English criminal had the right to escape punishment, including the death penalty, by agreeing to go to the colonialist war. Today, these words (taken out of context, dehistorized and, as a consequence, mythologized) have acquired a completely different meaning. Naturally, in this context, the metaphysical content of the word "patriotism" becomes rather relative, if not lost at all. If the Social in some form ceases to retain and reproduce metaphysical meanings, it can not act as a human form as well, although historically, of course, particular forms of social relations generated certain forms of being. Thus, for example, religion, of course, was originally the most important form of human that goes beyond the boundary conditions of existence of a slave society, but then, with the religion "anchored" (the term of Badiou which we will extend beyond the author's limits of its use) by institutionality, and the church institution anchored by the power of the large narrative, religion lost its metaphysical potential as a dominant form of spiritual production.

However, the nature of man remains metaphysical. M. Heidegger writes about this: "How does the metaphysics belong to man's nature? Metaphysically represented, man is constituted with facilities as a being among others. His essence constituted in such a way, his nature, the what and how of his Being, are in themselves metaphysical: animal (sensuousness) and rationale (nonsensuous). Thus confined to what is metaphysical, man is caught in the difference of

\footnotetext{
${ }^{2}$ Compare with the ontological status of art in traditional society.
} 
beings and Being which he never experiences. The manner of human representation which is metaphysically characterized finds everywhere only the metaphysically constructed world. Metaphysics belongs to the nature of man "[8. P. 178]. The Social ceases to be a form of human when it ceases to catch metaphysical meanings. We face a paradox: the Social can't not to be metaphysical by definition, but the crisis of sociality results in a situation when social physics (Mamardashvili) comes to the forefront and yet has not become the backbone of metaphysics and has lost the metaphysical horizon.

Social physics represents institutions and mechanisms necessary for any democratic society, they are similar to the rolled rails; moving along man can feel like a full member of this society. However, the problem is that these rails (too secure but devoid of "ephemeral" metaphysical content) turn into crutches for a socially immature man. They make him helpless in the situation labeled as risk society in social theory today. A man on crutches will never risk, therefore, he will be a victim of the environment created by others. These mechanisms do for him too much. These social crutches as frozen civilizational forms are devoid of the human metaphysical element. Physics without metaphysics, even social one, turns out to be dead and man-mortifying. Metaphysics as philosophy can actualize or negate the "empirical metaphysical potential" of any participant of social processes.

If the Social in philosophy was traditionally viewed as an area beyond metaphysics, as a reduction to social technology, today it is necessary to understand the Social as metaphysical, which can be done according to the logic of formation of the negative metaphysics. And the task does not imply creation of apology of the negative. The fact that any social phenomenon is ambivalent and sometimes its ambivalence can be brought to antinomy is the secret of Polichinelle. It is necessary to understand the negation of the Social as a source of the ontological, and, therefore, as an opportunity, a potency of the metaphysical. Heidegger stated: "Maybe we are struck by terrible blindness believing that the essence of the negative itself is something "negative" [9. P.101]. The task is to reveal the positive meanings of metaphysics of the negative, and some steps in the direction of performing it have already been taken. Negative anthropology and negative hermeneutics, atheology, non-history, and nonphilosophy were created after Heidegger and Sartre, after Negative Dialectics by Adorno and Kojeve's reading of Hegel. Some writings have been published recently - the works "The Social as a Negative" by Diana Gasparyan, "Nigitology of Culture" by Natalia Sayenko, "Metaphysics of Curved Paths" by Yuri Razinov, "Ontology of Lie" by Alexander Sekatsky, an "Ontology of the Negativity" collection. [10].

\section{CONCLUSION}

We conclude that to bring sociality as negativity to uncovering of the metaphysical component in the Social is an idea that needs to be developed. In our opinion, aesthetics of the Social may become one of the ways of such development. Aestheticization itself being a contradictory process makes birth of the Social in its immediate metaphysicity possible, as well as of creation of a particular discourse that allows us to diagnose and analyze this form of manifestation of the social.

\section{REFERENCES}

[1] The Social: origin, structural profiles, modern challenges / under the general editorship of P.K. Grechko, E.M. Kurmeleva. Moscow: ROSSPEN, 2009. 440 p.

[2] Konev V.A. Social philosophy. https://vk.com/doc11804567_318873093

[3] Sogomonov A.Yu. Paradoxes of dislocated time or how the social emerged / A.Yu.Sogomonov, P. Yu. Uvarov // Construction of the social. Europe. V-XVI centuries. / [Comp. by P. Yu. Uvarov, I.V. Dubrovsky]. Moscow: Editorial URSS, 2001. P. 135-159.

[4] Tereshchenko N.A. Social philosophy after "death of the social." Kazan: Kazan University, 2011. - 368 p.

[5] Latour B. Reassembling the Social : an Introduction to the ActorNetwork Theory / translation from English by I. Polonskaya; Ed. S. Gavrilenko; National Research University Higher School of Economics. - Moscow: Publishing House of the Higher School of Economics, 2014. - 384 p.

[6] Laclau E. The Impossibility of Society / E. Laclau // Logos. 2003. Number 4/5. P. 54-57.

[7] Baudrillard J. In the Shadow of the Silent Majority, or the End of the Social: translation from French/ J. J. Baudrillard. Ekaterinburg: Publishing house of Ural University, 2000. 95 p.

[8] Heidegger M. Overcoming metaphysics / Time and Being: Articles and Speeches / M. Heidegger; content by, translation from German, Introductory Article, comments and guidelines by V. V. Bibikhin. Moscow: Republic, 1993. P. 177-192.

[9] Heidegger M. Parmenides / translation from German A.P. Shurbelyov. St. Petersburg: Vladimir Dal, 2009. 384 p.

[10] Gasparyan D.E. Sociality as negativity. Moscow: KDU, 2007. 256 p .; Saenko N.R. Nigitology of culture (experience of construction). Volgograd: Publishing house of VSPU "Peremena", 2010. 218 p .; Razinov Yu.A. Metaphysics of Curved Paths: Essays on the Existential Nature of Truth and Delusion. Samara: Samara University Publishing House, 2011. 308 pp.; Ontology of negativity: Collection of scientific papers / publishing editor E.G. Dragalina-Chyornaya. Mjscow: "Canon +" ROOI "Rehabilitation", 2015. 376 p .; Sekatsky A.K. Ontology of lie. SPb .: Publishing house of St. Petersburg State University, 2000. 125 p. 